\title{
Characterization of amplification patterns and target genes on the short arm of chromosome 7 in early-stage lung adenocarcinoma
}

\author{
JI UN KANG \\ Department of Biomedical Laboratory Science, Korea Nazarene University, \\ Cheonan-si, Chungcheongnam-do 330-718, Republic of Korea \\ Received March 26, 2013; Accepted September 9, 2013
}

DOI: $10.3892 / \mathrm{mmr} .2013 .1686$

\begin{abstract}
Chromosomal alterations are a predominant genomic force contributing to the development of lung adenocarcinoma (ADC). High density genomic arrays were conducted to identify critical genetic landmarks that may be important mediators in the formation or progression of early-stage ADC. In this study, the most noteworthy and consistent observation was a copy number gain on the short arm of chromosome 7 , which was detected in $85.7 \%(12 / 14)$ of cases. Notably, three distinct regions of amplification were identified between the $7 \mathrm{p} 22.3$ and q11.2 regions in $28.6 \%$ (4/14) of cases; at a size of 4.1 Mbp (7p22.3-p21.1), 2.6 Mbp (7p15.2-p14.1) and 1.5 Mbp (7p12.3-p11.2). Variations of the 7 p11.2 locus that encodes EGFR are known to be oncogenic. Furthermore, potential target genes were identified that were previously not assumed to be involved in the pathogenesis of ADC, including CALM1P2 (7p11.2), HOXA4, HOXA5, HOXA6, HOXA7, HOXA9, HOXA10, HOXA11 and HOXA13 (7p15.2) and LOC442586, LOC442589, LOC442282, FAM2OC and LOC442651 (7p22.3). The present study determined critical regions on the $7 \mathrm{p}$ arm of chromosome 7 , which were implicated in ADC. The pattern of rearrangements on the $7 p$ arm may be a consequence of the high density of potential targets and the identified genes at the $7 p$ regions may aid in the development of therapeutic targets for ADC.
\end{abstract}

\section{Introduction}

Lung cancer is the most common form of malignancy and a major determinant of the overall cancer-related mortality worldwide (1). Based on the biology, therapy and prognosis,

Correspondence to: Professor Ji Un Kang, Department of Biomedical Laboratory Science, Korea Nazarene University, 456 Ssangyong 2(i)-dong, Seobuk-gu, Cheonan-si, Chungcheongnam-do 330-718, Republic of Korea

E-mail: jukang@kornu.ac.kr

Key words: early-stage lung adenocarcinoma, array-CGH, copy number gains, high-level amplifications lung cancers are divided into two predominant classes: non-small cell lung cancer (NSCLC) and small cell lung cancer (SCLC). NSCLCs consist of three types, adenocarcinoma (ADC), squamous cell carcinoma (SC) and large cell carcinoma (2).

Lung ADC, an epithelial cancer of glandular origin, is the most prevalent of these lung cancer diagnoses. In addition, due to the recent advances in computed tomographic technology, the number of patients diagnosed with small-sized lung ADC as well as stage I lung ADC has increased. To improve the prognosis of ADC patients, the identification of suitable markers is required to select patients with a poor prognosis who may benefit from adjuvant therapy subsequent to surgery $(3,4)$.

Gene amplification is a predominant genomic force contributing to the development of numerous solid tumors, including $\mathrm{ADC}$, and providing an important resource for identifying the location of candidate oncogenes (5). Previous genome-wide analyses for copy number changes in cancer cells have identified various chromosomal loci that are amplified in lung ADCs (5-7). However, as copy number alterations in lung ADC genomes are complex, target genes often remain unclear in amplified chromosomal segments. In addition, the clinical significance of gene amplification in early-stage lung ADC also remains to be elucidated. Thus, in the present study, the copy number changes of 14 early-stage lung ADCs were determined, with the aim of identifying novel high level alterations and candidate genes that may be important in ADC progression.

\section{Materials and methods}

Preparation of patient samples. Fourteen lung ADCs were observed from patients undergoing surgery as a primary treatment, without previous radiation or chemotherapy. The original diagnostic material of all ADC patients was reviewed to verify the previous histopathological diagnosis and staging according to the World Health Organization classification system. The stage of disease was based on the tumor-node-metastasis (TNM) classification using the UICC (Union Internationale Contre Le Cancer) staging system. No patients had received pre-operative chemotherapy or radiation. This study was reviewed and approved by the Institutional 
Review Board of the Chungnam National University Hospital (Daejeon, Korea). Written informed consent was obtained from each patient according to the institutional regulations of the Chungnam National University Hospital. The demographic and pathological data, including age, gender and the tumor stage were obtained by a review of the medical records.

Array-comparative genomic hybridization (CGH) analysis. Microarray-CGH was performed on the MacArray ${ }^{\mathrm{TM}}$ Karyo 4000 K BAC-chip (Macrogen, Seoul, Korea) (8-11), consisting of 4,046 human bacterial artificial chromosomes (BACs) applied in duplicate at a resolution of $1 \mathrm{Mbp}$ as described in our previous studies $(12,13)$. Briefly, all clones were two-end sequenced using an ABI Prism $3700{ }^{\circledR}$ DNA analyzer (Applied Biosystems, Foster City, CA, USA) and their sequences were blasted [using basic local alignment search tool (BLAST); http://blast.ncbi.nlm.nih.gov/Blast.cgi]. Mapping of large insert clones was conducted according to the genomic location in the UCSC Genome Bioinformatics database [http://genome. ucsc.edu; Build 36, version Mar. 2006 (hg18)].

Preparation of DNA targets, labeling, hybridization, washing, staining and scanning was conducted according to the manufacturer's instructions (Macrogen, Seoul, Korea) (8-13). Briefly, arrays were pre-hybridized with salmon sperm DNA to block repetitive sequences in the BACs. A total of $500 \mathrm{ng}$ normal male DNA (reference) and digested tumor DNA (test) were labeled with Cy5-dCTP and Cy3-dCTP, respectively, by randomly primed labeling (Array CGH Genomic Labeling System; Invitrogen, Carlsbad, CA, USA). The labeled probe and human Cot-I DNA (Invitrogen) were mixed and dissolved in hybridization solution.

Statistical analysis. To adjust for effects due to the variation between the red and green dyes, Lowess normalization was applied. The ratio of the red to green channels of each clone was calculated and $\log _{2}$ transformed. The spot quality criteria were set as foreground to background $>3.0$ and the standard deviation of triplicates $<0.2$. Breakpoint detection and status assignment of the genomic regions were performed using GLAD software (14). The R 2.2.1 package of the Bioconductor Project (http://www.bioconductor.org) was used for the detection of the frequency of gain or loss, and for statistical analysis. The median of the signal ratio (test signal/reference signal) of each triplicate spot was defined as a gain or a loss when it was $>0.25$ or $<-0.25$, respectively. High-level amplification of clones was defined when their intensity ratios were $>1.0$ in $\log _{2}$ scale and vice versa for homozygous deletion. The threshold value was determined empirically as a value 3 -fold greater than that of the standard deviations calculated from 30 normal males and females in hybridization experiments. The Benjamini-Hochberg false discovery rate (FDR) was applied for multiple testing correction for the high number of false-positive calls.

\section{Results}

Whole genome array analysis of ADC cases. To clarify the critical genetic markers associated with ADC pathogenesis, high-resolution array-CGH was conducted on 14 ADC cases. A broad range of aberrations were detected, such as dele-
Table I. A detailed overview of clinicopathological data of the 14 early-stage lung adenocarcinomas.

\begin{tabular}{lccccc}
\hline $\begin{array}{l}\text { Case } \\
\text { no. }\end{array}$ & Gender & $\begin{array}{c}\text { Age } \\
\text { (years) }\end{array}$ & $\begin{array}{c}\text { TNM } \\
\text { classification }\end{array}$ & $\begin{array}{c}\text { Tumor } \\
\text { stage }\end{array}$ & $\begin{array}{c}\text { Smoking } \\
\text { status }\end{array}$ \\
\hline 1 & M & 61 & T2N0M0 & 1B & Former smoker \\
2 & F & 50 & T2N2M0 & 3A & Current smoker \\
3 & F & 47 & T2N0M0 & 1B & Former smoker \\
4 & M & 66 & T1N0M0 & 1A & Current smoker \\
5 & M & 65 & T2N2M0 & 3A & Current smoker \\
6 & F & 61 & T1N0M0 & 1A & Never smoked \\
7 & F & 56 & T2N1M0 & 2B & Never smoked \\
8 & M & 72 & T1N0M0 & 1A & Former smoker \\
9 & M & 61 & T2N0M0 & 2A & Current smoker \\
10 & F & 70 & T2N2M0 & 3A & Former smoker \\
11 & M & 60 & T3N1M0 & 3A & Current smoker \\
12 & M & 70 & T3N1M0 & $3 \mathrm{~A}$ & Current smoker \\
13 & M & 75 & T3N1M0 & 3A & Current smoker \\
14 & F & 69 & T1N0M0 & 1A & Never smoked \\
\hline
\end{tabular}

TNM, tumor-node-metastasis.

tions and/or gains of various sizes. All patients (100.0\%) in this genomic profile showed multiple segmental alterations, including single copy as well as high level gains and losses. A detailed overview of the clinicopathological data of the 14 ADCs is shown in Table I. Although entire chromosomal arm changes appeared occasionally, the majority of copy number alterations in ADCs were localized regional changes. Notably, large copy number gains involving chromosomes $5 \mathrm{p}$, $7 \mathrm{p}, 20 \mathrm{q}, 1 \mathrm{p}$ and $16 \mathrm{p}$ ( $>35 \%$ of patients) were more prevalent than copy number losses in the cases. The delineation of the most frequently gained chromosomal regions and possible target genes in the ADCs is listed in Table II.

Copy number alterations on the short arm of chromosome 7 in ADCs. Array-CGH analysis revealed several copy number changes in the ADC cases. Initially, the analysis focused on the short arm of chromosome 7 , the most frequently affected regions in the ADC cases $(85.7 \%, 12 / 14)$. More specifically, three distinct regions of amplifications were identified in $28.6 \%(4 / 14)$ of the cases. In addition, three minimal overlapping regions were defined on chromosome $7 \mathrm{p}$, (7p22.3-p21.1, 7p15.2-p14.1) and 7p12.3-p11.2. The minimal common region of chromosome $7 \mathrm{p}$ was identified, by array-CGH, to be located between BAC41_H11 and BAC178_O13 (position 92.8-123.6 kb).

The first locus of amplification was located distally on 7p22.3-p21.1 regions (82.4-123.6 kb). According to the information archived by human genome database (http://genome. ucsc.edu/), it is flanked by the BAC clones between BAC130_ G18 and BAC113_E07 and contains 63 possible target genes (4.1 Mb segment). These terminal gains were often large and were located to the ETS translocation variant 1 (ETVI) gene. Notably, a high-frequency of single copy number gains $(>0.25$ $\log _{2}$ ratio) and high-level gains (>0.5 $\log _{2}$ ratio) from the 
Table II. Most frequently gained regions of overlap detected by microarray comparative genomic hybridization in early-stage lung adenocarcinomas and the candidate genes.

\begin{tabular}{|c|c|c|c|c|}
\hline BAC clone & $\begin{array}{l}\text { Chromosome } \\
\text { location }\end{array}$ & Gene contained in clones & $\begin{array}{l}\text { BAC size } \\
\quad(b p)\end{array}$ & $\begin{array}{l}\text { Cases with } \\
\text { copy number } \\
\text { gains }^{\mathrm{a}}(\%)\end{array}$ \\
\hline BAC91_J20 & $5 \mathrm{p} 15.33$ & SLC6A19, SLC6A18, TERT & 115,211 & 79 \\
\hline BAC151_L22 & $5 \mathrm{p} 15.33$ & Сер72,ТРPP & 89,632 & 71 \\
\hline BAC170_A22 & $7 \mathrm{p} 22.3$ & $\begin{array}{l}\text { MGC11257, LOC393076, GPR146, GPR30, } \\
\text { LOC402518 }\end{array}$ & 84,220 & 62 \\
\hline BAC1_I06 & $7 \mathrm{p} 11.2$ & CALMIP2 & 116,026 & 57 \\
\hline BAC15_B08 & $7 \mathrm{p} 11.2$ & EGFR & 100,083 & 57 \\
\hline BAC107_K11 & $20 q 13.33$ & ARFGAP1 , KIAA1510, CHRNA4, KCNQ2 & 147,123 & 54 \\
\hline BAC137_F15 & 7 p14.1 & $\begin{array}{l}\text { TRGJP1, TRGV11, TRGVB, TRGV10, TRGV9, } \\
\text { TRGVA, TRGV8, TRGV7, TRGV6, TRGV5P, } \\
\text { TRGV5, TRGV4 }\end{array}$ & 80,960 & 50 \\
\hline BAC147_B17 & $7 \mathrm{p} 22.3$ & MAD1L1, LOC402663, LOC442696, LOC442609 & 85,873 & 50 \\
\hline BAC218_N01 & $7 \mathrm{p} 15.2$ & $\begin{array}{l}\text { НОХА4, НОХА5, НОХА6, НОХА7, НОХА9, } \\
\text { НОХА10, НОХА11, НОХА13 }\end{array}$ & 111,540 & 43 \\
\hline BAC183_C18 & $7 \mathrm{p} 14.1$ & $\begin{array}{l}\text { LOC222103, TRGJP2, TRGC1, TRGJ1, TRGJP, } \\
\text { TRGJP1, TRGV11, TRGVB, TRGV10, TRGV9, } \\
\text { TRGVA, TRGV8, TRGV7, TRGV6, TRGV5P, } \\
\text { TRGV5 }\end{array}$ & 98,051 & 43 \\
\hline BAC38_N15 & $1 \mathrm{p} 36.33-1 \mathrm{p} 36.32$ & SKI, FLJ13941 & 85,791 & 43 \\
\hline BAC62_J14 & $7 \mathrm{p} 21.1$ & $H D A C 9$ & 78,272 & 43 \\
\hline BAC97_B23 & $7 \mathrm{p} 22.3$ & $\begin{array}{l}\text { OC442586, LOC442589, LOC442282, FAM20C, } \\
\text { LOC442651 }\end{array}$ & 94,921 & 43 \\
\hline BAC239_F18 & $16 \mathrm{p} 13.3$ & LOC441443, LOC389753 & 72,701 & 43 \\
\hline BAC142_O10 & $7 \mathrm{p} 22.3$ & $\begin{array}{l}\text { MAD1L1, LOC442699, LOC } 442592, \text { LOC } 442654, \\
\text { LOC442593, LOC442594, LOC442595, } \\
\text { LOC } 442700\end{array}$ & 144,899 & 43 \\
\hline BAC122_H21 & $7 \mathrm{p} 12.2$ & GRB10 & 85,692 & 43 \\
\hline BAC139_D05 & $7 \mathrm{p} 21.2$ & ETVI & 87,963 & 36 \\
\hline BAC161_H20 & $7 \mathrm{p} 14.3$ & PDEIC & 99,714 & 36 \\
\hline BAC178_O13 & $7 \mathrm{p} 11.2$ & LOC442681 & 92,874 & 36 \\
\hline BAC65_K10 & $7 \mathrm{p} 21.1$ & LOC442511, MEOX2 & 90,760 & 36 \\
\hline BAC46_P02 & $7 \mathrm{p} 13$ & CCM2, KIAA0363, TBRG4, RAMP3 & 91,839 & 36 \\
\hline
\end{tabular}

${ }^{\mathrm{a}}$ Alterations were defined by $\log _{2}$ ratio thresholds of 0.25 for copy number gains. Using this threshold, a frequency table was generated. BAC, bacterial artificial chromosome.

7p22.3-p21.1 region were detected in 71.4\% (10/14) and 35.7\% $(5 / 14)$ of the cases, respectively. The most frequently gained clone was BAC170_A22 at the 7p22.3 region $(57.1 \%, 8 / 14)$, which is located in the MGC11257, LOC393076, GPR146, GPR30 and LOC402518 genes.

The second candidate locus spanned $91.8-118.2 \mathrm{~kb}$ in the 7p15.2-p14.1 regions, encompassed 15 target clones and was identified as exhibited copy number gains in 7 of 14 cases (50.0\%). ADC cases with 7p14.1-p15.2 gains, displayed a varying degree of copy number increases predominantly from $7 \mathrm{p} 14.1(50 \%, 7 / 14), 7 \mathrm{p} 15.2(42.9 \%, 6 / 14)$ and $7 \mathrm{p} 14.3$ $(35.7 \%, 5 / 14)$. It was flanked by the BAC clones between BAC137_F15 and BAC218_N01, and encompassed 57 genes (http://genome.ucsc.edu/). Notably, a $111.5 \mathrm{~kb}$ high-level amplification of the 7 p15.2 region contained HOXA4,
HOXA5, HOXA6, HOXA7, HOXA9, HOXA10, HOXA11 and HOXA13 genes in one case.

The third region was flanked by BAC157_N08 and BAC178_O13, and mapped at the 7p11.2-p12.3 regions (76.0-92.9 kb). A high frequency of single copy number gains $\left(>0.25 \log _{2}\right.$ ratio) from the 7 p11.2-p12.3 regions was observed in $57.1 \%(8 / 14)$ of the cases. In addition, two amplified ( $>1$ $\log _{2}$ ratio) loci on the 7 p11.2 region were identified in $14.3 \%$ of the cases. One locus contained contiguous amplified clones covering a region of $\sim 100.1 \mathrm{~kb}$ and comprised the oncogenic variant of the epidermal growth factor receptor (EGFR) gene in 2 of 14 ADCs (14.3\%), with the highest level of amplification in case 13 (Fig. 2).

Furthermore, a candidate target gene for $C A L M 1 P 2$ was identified in $14.3 \%(2 / 14)$ of cases at the 7 p11.2 region. To the 


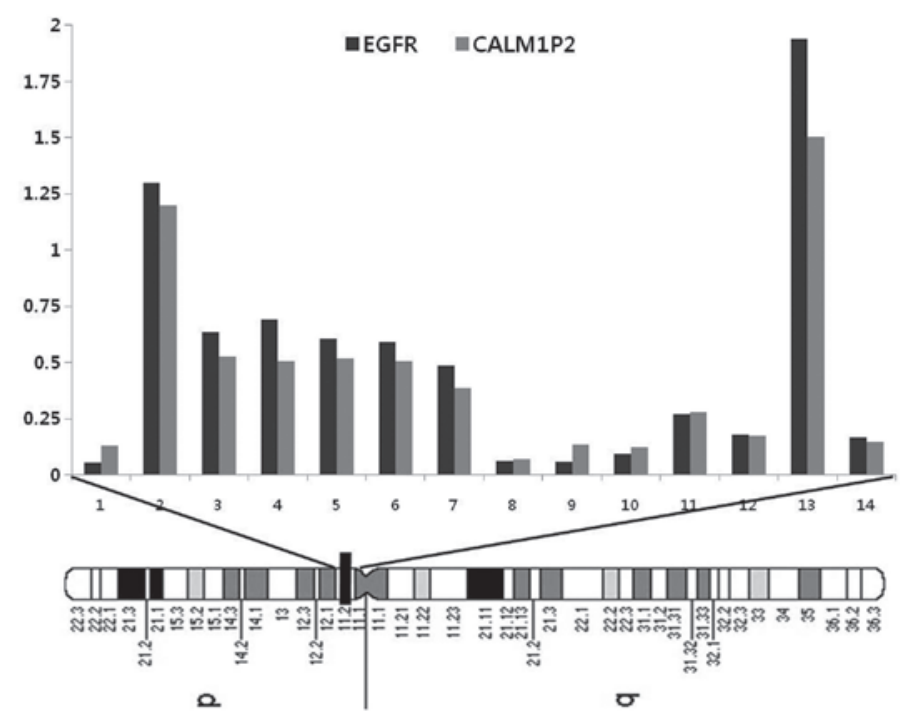

Figure 1. Individual profile at the 7p11.2 region in the 14 ADC cases. High-level amplifications are shown in cases 2 and 13 . The schematic presentation of cytogenetic bands, as well as the map position is shown below the plot. ADC, adenocarcinoma.

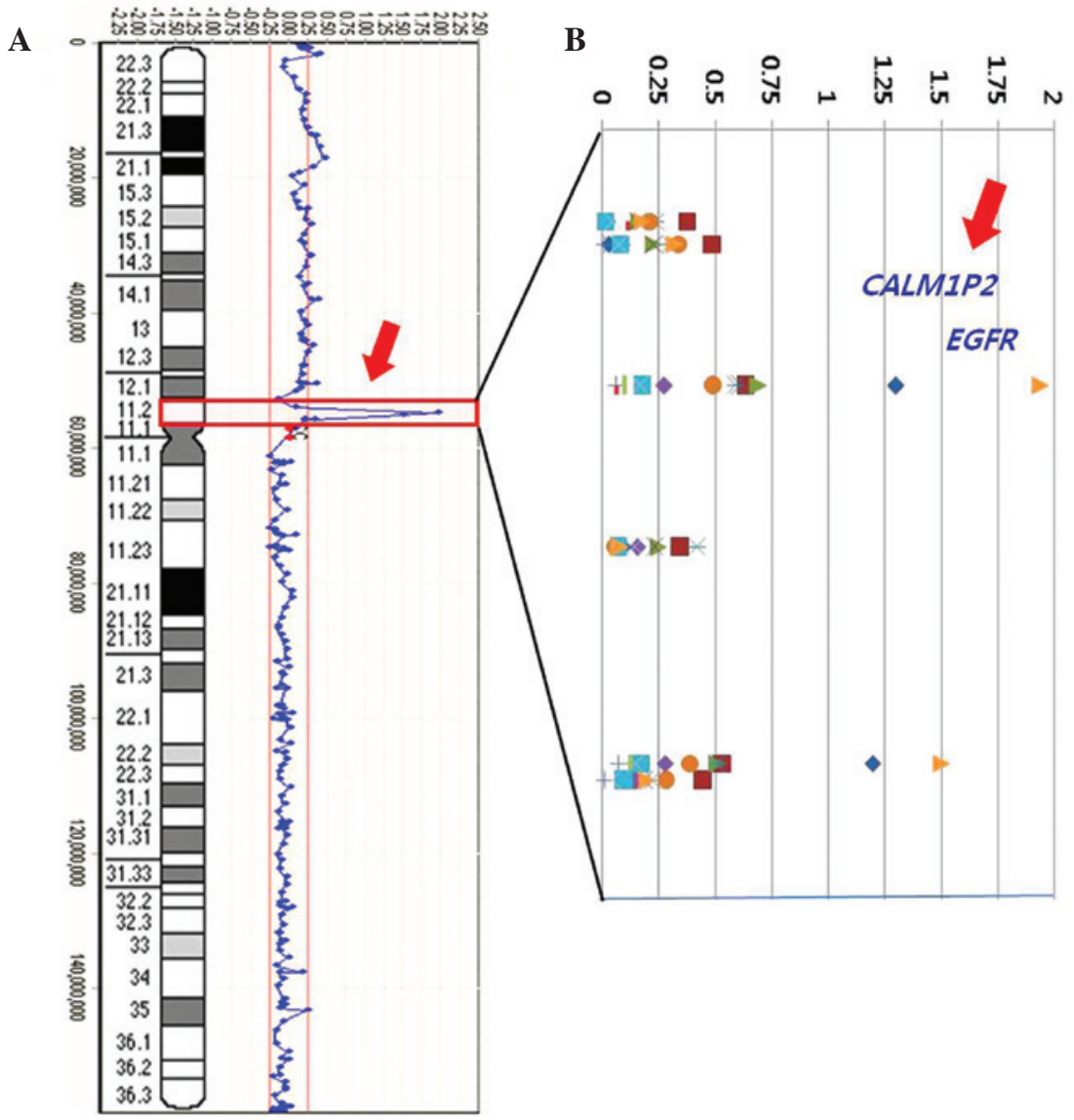

Figure 2. (A) Frequency (\%) diagram for chromosome 7 generated from combined scores of the 14 ADC cases. $\log _{2}$ ratio was $>1$ in the BAC clone, suggesting copy number amplifications at the 7p11.2 region (highlighted in red). Cytobands in the ideogram are shown on the left. (B) Weighted frequency (\%) diagram of the 7p11.2 region from the ADC cases. In the intensity ratio profiles, the $y$-axis represents the map position of the corresponding clone and the intensity ratios are assigned to the $\mathrm{x}$-axis. ADC, adenocarcinoma; $\mathrm{BAC}$, bacterial artificial chromosome.

best of our knowledge, the pathogenesis of the CALM1P2 gene has not been previously reported in ADCs. As increased amplification of the EGFR gene has been previously observed in ADCs, the present study aimed to determine whether there was a correlation between $E G F R$ and the newly identified CALMIP2 gene. Notably, co-amplifications were demonstrated between EGFR and CALM1P2 genes in 100\% (2/2, case 2 and 13; Fig. 1). An example of an individual profile at the $7 \mathrm{p} 11.2$ 
region in the $14 \mathrm{ADC}$ cases is presented in Fig. 1. High-level amplifications are clearly observed in cases 2 and 13. Fig. 2A represents the frequency of the copy number changes on chromosome 7 and a weighted frequency (\%) diagram with high-level amplifications at the 7p11.2 region from the 14 ADC cases is shown in Fig. 2B.

\section{Discussion}

Array-CGH is a successful and valuable tool for the analysis of chromosome copy-number alterations in human cancer and may be suitable for individualized diagnostic, prognostic and therapeutic decision-making (12). In this study, genome wide array-CGH was conducted to comprehensively characterize genome copy number aberrations associated with early-stage ADC.

The most noteworthy observation in this study was the high frequency of copy number gains at chromosome $7 \mathrm{p}$, in $85.7 \%(12 / 14)$ of the cases. The short arm of chromosome 7 is implicated as being involved in the initiation and/or progression of ADC and has been suggested to include critical cancer related genes in ADC (16-18). Job et al (15) demonstrated that the high frequency of copy number gains on chromosome 7p contained CARD11, ETVI and IKZF1 genes in 78-92\% of the ADCs observed. Single nucleotide polymorphism array analysis determined the high-level amplifications on chromosome 7p (>10\%) in small-sized ADCs and lung ADC cell lines (3). Previously, frequent copy number gains on chromosome $7 \mathrm{p}$ in ADC cases in non-smokers has also been observed (16). In conclusion, chromosome $7 \mathrm{p}$ appears to harbor multiple tumor-related genes that may be implicated in ADC pathogenesis.

Three distinct amplified ( $>1 \log _{2}$ ratio) loci from the $7 \mathrm{p} 22.3-11.2$ region were identified in $28.6 \%$ of the cases. The first loci located on 7p22.3 contained FAM20C, LOC442586, LOC442589, LOC442282 and LOC442651 genes. The FAM20 family of secreted proteins consists of three members (FAM20A, FAM20B and FAM20C) which have recently been linked to developmental disorders (17).

The second amplification region of $7 \mathrm{p} 15.2$ contained HOXA4, HOXА5, НOXА6, НOXА7, НOXА9, НОХА10, HOXA11 and HOXA13 genes. Homeobox (HOX) genes encode homeodomain-containing transcription factors critical for development, differentiation and homeostasis. Their dysregulation has been implicated in various types of cancer, including lung adenocarcinoma. Abe et al (18) determined that the expression levels of $H O X A 5$ and $A 10$ in adenocarcinoma (and $H O X A 1, A 5, A 10$ and $C 6$ in squamous cell carcinoma of the lung) were significantly higher than those in the noncancerous tissues. It was suggested that the disordered patterns of $H O X$ gene expression were involved in the development of non-small cell lung cancer and in the histological changes (such as adenocarcinoma and squamous cell carcinoma) of the lung. A previous study by Marra et al (19) observed the involvement of the $H O X B 13$ gene in several tumors of the urogenital system. In non-muscle invasive bladder transitional cancer, nuclear HOX B13 expression showed significant correlation with higher Gleason grade, clinical stage of the tumor and a poor survival outcome, thus determining its potential prognostic value.
HOX genes have also been demonstrated to be a hallmark of numerous hematological malignancies (20). The dysregulation of $H O X$ genes is correlated with a number of hematological malignancies, including acute myeloid leukemia (AML) and acute lymphoid leukemia, where they have been shown to support the immortalization of leukemic cells as chimeric partners in fusion genes and when overexpressed in their wild-type form (21). Furthermore, overexpression of individual Hox proteins expanded various bone marrow populations in vitro, leading to myeloproliferation and in certain cases inhibition of differentiation and AML in vivo (22). A high concentration of $H O X A 9$ gene product in leukemic blasts has been shown to be an adverse prognostic parameter and HOXA9 expression was associated with a certain state of myeloid differentiation (23). These results suggest that $H O X$ genes represent important prognostic and predictive markers for solid tumors and may be rational targets for therapeutic approaches for the poor prognosis leukemia subset. Additional studies are required to further investigate the mechanism and clinical significance of these results.

The third amplification region was located distally in the 7 p22.3 chromosomal region and this locus contained the oncogenic variant of the epidermal growth factor receptor gene $(E G F R)$ in $7.1 \%$ of the cases. The involvement of the EGFR gene as the driver of the 7p11.2 amplicon is well established in ADC cases (24-27).

Liu et al (24) determined that EGFR gene mutation rates were significantly greater in patients with adenocarcinoma (35.5 versus $9.9 \%$ non-adenocarcinoma) and there was a correlation between EGFR gene mutation and gene amplification, particularly in early-stage adenocarcinoma. Moreover, Reinmuth et al (25) demonstrated that EGFR gene mutations are frequently observed in ADC with bronchioloalveolar differentiation and may be linked to chromosomal imbalances. In a study by Sholl et al (26), EGFR amplification demonstrated a unique association with exon 19 deletion mutations and represented distinct clinicopathological features associated with a significantly worsened prognosis in ADC patients. Furthermore, Yoshizawa et al (27) observed that EGFR mutations were significantly associated with adenocarcinoma in situ, minimally invasive adenocarcinoma and lepidic- and papillary-predominant adenocarcinoma, suggesting that EGFR mutations may aid in the prediction of patient prognosis and selection of those who require adjuvant chemotherapy. These results and the results of the present study suggested that the EGFR mutation may be an early event in the pathogenesis of lung ADC and may facilitate aggressive behavior of the tumor.

In addition, a potential oncogenic variant of $C A L M 1 P 2$ was identified in $14.3 \%(2 / 14)$ of cases from the $7 \mathrm{p} 11.2$ region. To the best of our knowledge, the involvement of the CALM1P2 gene in the pathogenesis of ADC has not been previously described; however, genetic mutations of CALM genes are observed in other types of cancer $(28,29)$. Toutenhoofd et al (28) concluded that the CALM gene family is differentially active at the transcriptional level in teratoma cells and that the 5' untranslated regions are required to recover full promoter activation. Furthermore, Stanislaus et al (29) suggested that the CALM1 and PLCG2 signaling pathways are the two potential targets for gene knockdown in doxorubicin- and paclitaxel-based 
chemotherapy of cervical cancer. As a gain of amplification of the EGFR gene has been described previously in ADCs, the present study aimed to determine whether there was a correlation between the EGFR gene and the newly identified amplified $C A L M 1 P 2$ gene. Notably, co-amplification was demonstrated between the EGFR and CALMIP2 genes in $100 \%(2 / 2)$ of cases.

The present study established critical regions on the $7 \mathrm{p}$ chromosome implicated in ADC. The present results warrant future studies to identify the putative oncogenes at $7 p$ to gain a better understanding of the molecular pathogenesis of early-stage lung ADC. The genomic analysis allowed the proposition of novel candidate genes that may be associated with the pathogenesis of early-stage lung adenocarcinoma. The newly identified target genes may contribute to ADC pathogenesis as well as provide novel targets for therapeutic intervention in early-stage ADC pending functional validation.

\section{Acknowledgements}

This study was funded by the research fund of Korea Nazarene University in 2013 (2013-0302).

\section{References}

1. Parkin DM, Bray FI and Devesa SS: Cancer burden in the year 2000. The global picture. Eur J Cancer 37 (Suppl 8): S4-S66, 2001.

2. Balsara BR, Sonoda G, du Manoir S, Siegfried JM, Gabrielson E and Testa JR: Comparative genomic hybridization analysis detects frequent, often high-level, overrepresentation of DNA sequences at 3q, 5p, 7p, and $8 \mathrm{q}$ in human non-small cell lung carcinomas. Cancer Res 57: 2116-2120, 1997.

3. Iwakawa R, Kohno T, Kato M, Shiraishi K, Tsuta K, Noguchi M, Ogawa S and Yokota J: MYC amplification as a prognostic marker of early-stage lung adenocarcinoma identified by whole genome copy number analysis. Clin Cancer Res 15: 1481-1489, 2011.

4. Greulich H: The genomics of lung adenocarcinoma: opportunities for targeted therapies. Genes Cancer 1: 1200-1210, 2010.

5. Zhao X, Weir BA, LaFramboise T, Lin M, Beroukhim R, Garraway L, Beheshti J, Lee JC, Naoki K, Richards WG, et al: Homozygous deletions and chromosome amplifications in human lung carcinomas revealed by single nucleotide polymorphism array analysis. Cancer Res 1: 5561-5570, 2005.

6. Tonon G, Wong KK, Maulik G, Brennan C, Feng B, Zhang Y, Khatry DB, Protopopov A, You MJ, Aguirre AJ, et al: High-resolution genomic profiles of human lung cancer. Proc Natl Acad Sci USA 102: 9625-9630, 2005.

7. Li X, Wan L, Shen H, Geng J, Nie J, Wang G, Jia N, Dai M and Bai X: Thyroid transcription factor-1 amplification and expressions in lung adenocarcinoma tissues and pleural effusions predict patient survival and prognosis. J Thorac Oncol 7: 76-84, 2012.

8. Hwang KT, Han W, Cho J, Lee JW, Ko E, Kim EK, Jung SY, Jeong EM, Bae JY, Kang JJ et al: Genomic copy number alterations as predictive markers of systemic recurrence in breast cancer. Int J Cancer 15: 1807-1815, 2008.

9. Choe J, Kang JK, Bae CJ, Lee DS, Hwang D, Kim KC, Park WY, Lee JH and Seo JS: Identification of origin of unknown derivative chromosomes by array-based comparative genomic hybridization using pre- and postnatal clinical samples. J Hum Genet 52: 934-942, 2007.

10. Kim JI, Ju YS, Park H, Kim S, Lee S, Yi JH, Mudge J, Miller NA, Hong D, Bell CJ et al: A highly annotated whole-genome sequence of a Korean individual. Nature 20: 1011-1015, 2009.

11. Chochi Y, Kawauchi S, Nakao M, Furuya T, Hashimoto K, Oga A, Oka M and Sasaki K: A copy number gain of the $6 \mathrm{p}$ arm is linked with advanced hepatocellular carcinoma: an array-based comparative genomic hybridization study. J Pathol 217: 677-684, 2009 .
12. Kang JU, Koo SH, Kwon KC, Park JW and Kim JM: Identification of novel candidate target genes, including EPHB3, MASP1 and SST at 3q26.2-q29 in squamous cell carcinoma of the lung. BMC Cancer 9: 237, 2009.

13. Kang JU and Koo SH: ORAOV1 is a probable target within the 11q13.3 amplicon in lymph node metastases from gastric adenocarcinoma. Int J Mol Med 29: 81-87, 2012.

14. Willenbrock $\mathrm{H}$ and Fridlyand J: A comparison study: applying segmentation to array CGH data for downstream analyses. Bioinformatics 21: 4084-4091, 2005.

15. Job B, Bernheim A, Beau-Faller M, Camilleri-Broët S, Girard P, Hofman P, Mazières J, Toujani S, Lacroix L, Laffaire J, et al: Genomic aberrations in lung adenocarcinoma in never smokers. PLoS One 5: e15145, 2010.

16. Thu KL, Vucic EA, Chari R, Zhang W, Lockwood WW, English JC, Fu R, Wang P, Feng Z, MacAulay CE, et al: Lung adenocarcinoma of never smokers and smokers harbor differential regions of genetic alteration and exhibit different levels of genomic instability. PLoS One 7: e33003, 2012.

17. Vogel P, Hansen GM, Read RW, Vance RB, Thiel M, Liu J, Wronski TJ, Smith DD, Jeter-Jones S and Brommage R: Amelogenesis imperfecta and other biomineralization defects in Fam20a and Fam20c null mice. Vet Pathol 49: 998-1017, 2012.

18. Abe M, Hamada J, Takahashi O, Takahashi Y, Tada M, Miyamoto M, Morikawa T, Kondo S and Moriuchi T: Disordered expression of HOX genes in human non-small cell lung cancer. Oncol Rep 15: 797-802, 2006.

19. Marra L, Cantile M, Scognamiglio G, Perdonà S, La Mantia E, Cerrone M, Gigantino V, Cillo C, Caraglia M, Pignata S, et al: Deregulation of HOX B13 expression in urinary bladder cancer progression. Curr Med Chem 20: 833-839, 2013.

20. Bach C, Buhl S, Mueller D, García-Cuéllar MP, Maethner E and Slany RK: Leukemogenic transformation by HOXA cluster genes. Blood 115: 2910-2918, 2010.

21. Alharbi RA, Pettengell R, Pandha HS and Morgan R: The role of HOX genes in normal hematopoiesis and acute leukemia. Leukemia 27: 1000-1008, 2013.

22. Eklund E: The role of Hox proteins in leukemogenesis: insights into key regulatory events in hematopoiesis. Crit Rev Oncog 16: 65-76, 2011 .

23. Golub TR, Slonim DK, Tamayo P, Huard C, Gaasenbeek M, Mesirov JP, Coller H, Loh ML, Downing JR, Caligiuri MA, et al: Molecular classification of cancer: class discovery and class prediction by gene expression monitoring. Science 286: 531-537, 1999.

24. Liu H, Li Y, Chen G, Wang J, Li Y, Wang Y, Wei S, Zhu D, Qiu X, Wang W, et al: Detection and its clinical significance of EGFR gene mutation and gene amplification in 187 patients with non-small cell lung cancer. Zhongguo Fei Ai Za Zhi 12: 1219-1228, 2009 (In Chinese).

25. Reinmuth N, Jauch A, Xu EC, Muley T, Granzow M, Hoffmann H, Dienemann H, Herpel E, Schnabel PA, Herth FJ,et al: Correlation of EGFR mutations with chromosomal alterations and expression of EGFR, ErbB3 and VEGF in tumor samples of lung adenocarcinoma patients. Lung Cancer 62: 193-201, 2008.

26. Sholl LM, Yeap BY, Iafrate AJ, Holmes-Tisch AJ, Chou YP, Wu MT, Goan YG, Su L, Benedettini E, Yu J, et al: Lung adenocarcinoma with EGFR amplification has distinct clinicopathologic and molecular features in never-smokers. Cancer Res 69: 8341-8348, 2009.

27. Yoshizawa A, Sumiyoshi S, Sonobe M, Kobayashi M, Fujimoto M, Kawakami F, Tsuruyama T, Travis WD, Date H and Haga H: Validation of the IASLC/ATS/ERS lung adenocarcinoma classification for prognosis and association with EGFR and KRAS gene mutations: analysis of 440 Japanese patients. J Thorac Oncol 8: 52-61, 2013.

28. Toutenhoofd SL, Foletti D, Wicki R, Rhyner JA, Garcia F, Tolon R and Strehler EE: Characterization of the human CALM2 calmodulin gene and comparison of the transcriptional activity of CALM1, CALM2 and CALM3. Cell Calcium 23: 323-338, 1998.

29. Stanislaus A, Bakhtiar A, Salleh D, Tiash S, Fatemian T, Hossain S, Akaike T and Chowdhury EH: Knockdown of PLC-gamma-2 and calmodulin 1 genes sensitizes human cervical adenocarcinoma cells to doxorubicin and paclitaxel. Cancer Cell Int 12: 30, 2012. 